\section{Role of nerve growth factor and tropomyosin receptor kinase $A$ in the pathogenesis of osteoarthritis. Might nerve growth factor be the link interwinding obesity and osteoarthritis?}

We read with interest the paper by Nwosu $e t$ al ${ }^{1}$ recently published in Annals of the Rheumatic Diseases. They clearly provided evidence that blocking tropomyosin receptor kinase A (TrkA), the p140 high-affinity receptor of nerve growth factor (NGF), by a selective TrkA inhibitor AR786 relieves pain in two different rat models of osteoarthritis (OA). A reduction of synovitis was also shown by histopathology, suggesting that NGF inhibition exerted its effect at peripheral level on extraneural tissues. Authors concluded that inhibition of NGF activity might be an effective strategy as treatment of OA pain. Indeed, NGF may have pleiotropic effects, and we would like to speculate on the possible role played by NGF and its counter-receptor TrkA also in cartilage metabolism. Some years ago, we showed that human chondrocytes synthesise NGF and TrkA, and that their expression is regulated in OA cartilage. ${ }^{2}$ We studied the articular cartilage from three healthy donors (HDs) and 12 patients with OA undergoing surgical knee replacement. According to the extent of macroscopic and microscopic (Mankin score) damage, OA cartilage was split in two zones showing the lowest (low) and highest (high) degree of anatomic injury. Flow cytometry analysis on freshly isolated chondrocytes showed an increasing expression of intracellular TrkA from HD cartilage $(3.4 \pm 1 \%)$ to low $(31 \pm 11 \%)$ and high OA cartilage $(41.4 \pm 19 \%)$, respectively $(\mathrm{p}<0.01)$. Likewise, chondrocyte NGF expression was significantly higher in high $(41.3 \pm 25 \%)$ or $\min (21.3 \pm 12 \%)$ OA cartilage than in HDs $(3.8 \pm 2.4 \%, \mathrm{p}<0.01)$. The autocrine production of NGF by chondrocytes was further confirmed by real time-polymerase chain reaction (RT-PCR), detecting higher NGF mRNA expression in OA cartilage. NGF and its receptor TrkA are also produced by human adipocytes from white adipose tissue. ${ }^{3}$ These findings have been further confirmed, and an increase in NGF plasma levels in obese women correlating with body mass index (BMI) and inflammatory markers was also reported. ${ }^{4}$ We are focusing on possible inter-relations between cartilage damage, BMI and NGF in human OA. ${ }^{5}$ We analysed knee articular cartilage from 19 obese patients with OA (13 female, BMI $31-37 \mathrm{~kg} / \mathrm{m}^{2}$, age $41-84$ years) and 10 normal-weight patients with OA (six female, BMI $21-23 \mathrm{~kg} / \mathrm{m}^{2}$, age 28-73 years). Cartilage injury was assessed by Osteoarthritis Research Society International (OARSI) score ${ }^{6}$ and NGF expression by semiquantitative immunohistochemistry and real-time quantitative reverse-transcriptase polymerase chain reaction (RTQ-PCR) analysis. We found a significant correlation between OARSI score and BMI ( $\mathrm{r}=0.64,95 \%$ CI 0.35 to 0.82$)$. Immunohistochemistry showed a correlation between NGF expression and BMI $(\mathrm{r}=0.76,95 \% \mathrm{CI} 0.53$ to 0.88$)$ or OARSI score $(\mathrm{r}=0.82,95 \%$ CI 0.65 to 0.91$)$. These findings were confirmed by RTQ-PCR analysis.

The role of NGF in chondrocyte metabolism is unknown, but being adult cartilage aneural, it is conceivable that it is not linked to perception of pain or other nervous system-related functions. Like in other cells, ${ }^{3}{ }^{7}$ NGF might interact with growth factors and cytokines such as tumour necrosis factor (TNF)alpha and transforming growth factor (TGF)B-1, whose role in the pathophysiology of cartilage has been extensively studied. ${ }^{8}$ Although Nwosu et al did not detect any impact on cartilage in OA rats by TrkA inhibition, we believe the TrkA/ NGF targeting may represent a promising strategy in the treatment of OA, including pain.

Florenzo lannone, ${ }^{1}$ Simone Perniola, ${ }^{1}$ Giuseppe Lopalco, ${ }^{1}$ Luca Cantarini, ${ }^{2}$ Giovanni Lapadula ${ }^{1}$

${ }^{1}$ Rheumatology Unit, University of Bari, Bari, Italy

${ }^{2}$ Rheumatology Unit, University of Siena, Siena, Italy

Correspondence to Professor Florenzo lannone, School of Medicine, University of Bari, P.zza G. Cesare 11, Bari 70124, Italy; florenzo.iannone@uniba.it

Citation: Nwosu LN, Mapp PI, Chapman V, et al. Blocking the tropomyosin receptor kinase $\mathrm{A}$ (TrkA) receptor inhibits pain behaviour in two rat models of osteoarthritis. Ann Rheum Dis 2015:201420720 (Basic and translational research)

Competing interests None declared.

Provenance and peer review Not commissioned; internally peer reviewed.

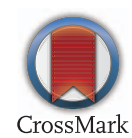

To cite lannone F, Perniola S, Lopalco G, et al. Ann Rheum Dis 2015;74:e70.

Accepted 2 September 2015

Published Online First 18 September 2015

\section{S Linked}

http://dx.doi.org/10.1136/annrheumdis-2015-208523

Ann Rheum Dis 2015;74:e70. doi:10.1136/annrheumdis-2015-208519

\section{REFERENCES}

1 Nwosu LN, Mapp PI, Chapman V, et al. Blocking the tropomyosin receptor kinase A (TrkA) receptor inhibits pain behaviour in two rat models of osteoarthritis. Ann Rheum Dis 2015. Published Online First 18 Aug 2015. doi.org/10.1136/ annrheumdis-2014-207203

2 lannone F, De Bari C, Dell'Accio F, et al. Increased expression of nerve growth factor (NGF) and high affinity NGF receptor (p140 TrkA) in human osteoarthritic chondrocytes. Rheumatology (Oxford) 2002;41:1413-18.

3 Peeraully MR, Jenkins JR, Trayhurn P. NGF gene expression and secretion in white adipose tissue: regulation in 3T3-L1 adipocytes by hormones and inflammatory cytokines. Am J Physiol Endocrinol Metab 2004;287:E331-9.

4 Bulló M, Peeraully MR, Trayhurn $\mathrm{P}$, et al. Circulating nerve growth factor levels in relation to obesity and the metabolic syndrome in women. Eur J Endocrinol 2007:157:303-10.

5 Perniola S, Lacarpia N, Bizzoca R, et al. Role of obesity in the expression of cytokines and metalloproteinases in human osteoarthritis chondrocytes. Ann Rheum Dis 2014;73(Suppl 2);797.

6 Gerwin N, Bendele AM, Glasson S, et al. The OARSI histopathology initiativerecommendations for histological assessments of osteoarthritis in the rat. Osteoarthritis Cartilage 2010;18(Suppl 3):S24-34.

7 Cosgaya JM, Aranda A. Nerve growth factor regulates transforming growth factor-beta 1 gene expression by both transcriptional and posttranscriptional mechanisms in PC12 cells. J Neurochem 1995;65:2484-90.

8 lannone F, Lapadula G. Obesity and inflammation-targets for OA therapy. Curr Drug Targets 2010;11:586-98. 